\title{
Early Versus Delayed Laparoscopic Cholecystectomy for Uncomplicated Acute Cholecystitis
}

\author{
Abdallah M Taha ${ }^{1}$, Mohamed Yousef A. ${ }^{2,}$, , Asmaa Gaber R. ${ }^{1}$ \\ ${ }^{1}$ Department of General Surgery, Faculty of Medicine, South Valley University, Qena, Egypt \\ ${ }^{2}$ Department of General Surgery, Faculty of Medicine, Aswan University, Aswan, Egypt
}

\section{Email address:}

myousef76@gmail.com (Mohamed Y. A.)

${ }^{*}$ Corresponding author

\section{To cite this article:}

Abdallah M Taha, Mohamed Yousef A., Asmaa Gaber R. Early Versus Delayed Laparoscopic Cholecystectomy for Uncomplicated Acute Cholecystitis. Journal of Surgery. Special Issue: Surgical Infections and Sepsis. Vol. 4, No. 3-1, 2016, pp. 29-33. doi: $10.11648 /$ j.js.s.2016040301.16

Received: March 16,2016; Accepted: March 17, 2016; Published: April 18, 2016

\begin{abstract}
Introduction: Acute cholecystitis is a relatively common complication of gallstones It can lead to significant morbidity and mortality from potentially life-threatening complications such as empyema, gallbladder gangrene and gallbladder perforation It presents as a surgical emergency and usually requires hospitalization for management Laparoscopic cholecystectomy is advocated for acute cholecystitis; however, the timing of cholecystectomy and the value of the additional treatments have been a matter of controversy Aim: To compare the outcome of early versus delayed laparoscopic cholecystectomy in cases of non-complicated acute cholecystitis, as its place remains controversial in the management of acute cholecystitis due to a high reported incidence of bile leaks and conversion rate Design: Prospective interventional comparative study Methods: 120 Patients admitted to Qena and Aswan universities' hospitals with acute cholecystitis over two years period (2013-2015) were included in this study An early laparoscopic cholecystectomy (ELC), within 7 days from onset of symptoms, for 50 patients, and delayed Laparoscopic cholecystectomy (DLC) after 6 weeks of conservative treatment for 70 patients was performed Demographic details, operative findings, conversion to open surgery, operative time, complications, timing of endoscopic retrograde cholangiopancreatography (ERCP) and hospital stay for all those patients were recorded Statistical analysis was performed by SPSS version 18 Results: There was insignificant difference in the conversion rates (2 in ELC group versus 2 DLC group, $p$ value: 0.555 ), post-operative hospital stay (2 days vs 1.5 days, $p$ value: 0.375 ) However, operative time was significantly more in the ELC group (85 minutes versus 70 minutes, $p$ value: 0.023 ) Postoperative ERCP was required in 2 patients in ELC group and one patient in DLC group Pre-operative ERCP was required in 2 patients in delayed group $40 \%$ of patients (48) had previous admissions with similar symptoms Conclusion: ELC for uncomplicated acute cholecystitis is technically demanding surgery, but it is safe and do not have increased complication rate than DLC It decreases re-admission rate and overall hospital stay.
\end{abstract}

Keywords: Acute, Cholecystectomy, Laparoscopic

\section{Introduction}

Laparoscopic cholecystectomy is widely established as the standard operation in acute cholecystectomy [1] The traditional teaching has been a two-stage treatment for acute cholecystitis with an initial conservative management followed by an interval laparoscopic cholecystectomy [2] Laparoscopic cholecystectomy is avoided for acute cholecystitis due to concerns about the potential hazards of complications, especially common bile duct injury and a high conversion rate to open cholecystectomy [3] The conversion rates for elective laparoscopic cholecystectomy range from $3-7 \%$ [4] However, in the presence of acute inflammation, higher conversion rates of up to $30 \%$ have been reported [5-6] Timing of surgery in acute cholecystitis has been controversial Several studies have reported favorable outcomes with a low conversion rate if patients are operated within 96 hours of admission After that window period, surgeons have opted for interval cholecystectomy after a 
period of 6-8 weeks [7] Larger surgical centres have published their successful management of acute cholecystitis with urgent laparoscopic cholecystectomy [8] Since most surgeons prefer to delay surgery during the acute phase, we performed this prospective study to compare the outcome of early and delayed laparoscopic cholecystectomy in the treatment of uncomplicated acute cholecystitis.

\section{Objectives}

To compare the outcome of early versus delayed laparoscopic cholecystectomy in cases of non-complicated acute cholecystitis, as its place remains controversial in the management of acute cholecystitis due to a high reported incidence of bile leaks and conversion rate.

\section{Patients and Methods}

Between October 2013 and November 2015, 120 patients admitted to general surgery, internal medicine and gastroenterology departments with acute cholecystitis in South Valley and Aswan universities' hospitals were included in this study An early laparoscopic cholecystectomy (ELC), within 7 days from onset of symptoms, for 50 patients, and delayed laparoscopic cholecystectomy (DLC) for 70 patients after 6 weeks was performed upon patient choice after adequate patient consultation, and understanding of benefits and drawbacks of each procedure 5 patients had another acute attack during waiting time for DLC group 10 patients lost follow up, 3 patients develops acute pancreatitis and 5 patients needs emergent cholecystectomy in the follow-up period of patients allocated for DLC, Those patients were deleted from DLC group Complicated acute cholecystitis, patients with common bile duct (CBD) stones, diabetic patients and patients receiving immunosuppressive drugs are excluded from this study.

Abdominal ultrasonography was done for all patients admitted with the provisional diagnosis of acute cholecystitis Diagnosis of acute cholecystitis was based on the presence of persistent right upper quadrant pain for more than 6 hours, with or without fever, with evidence of raised inflammatory markers above normal values, i.e white cell count and/or Creactive protein, presence of ultrasonographic abnormalities (gall stones, thick-walled gall bladder, pericholecystic fluid collection, and positive Murphy's sign)

Demographic data, operative time, starting from incision for the optical port to closure of port sites, conversion to open surgery, hospital stay, timing of endoscopic retrograde cholangiopancreatography (ERCP) and complications for all those patients were recorded.

We used the standard four-port technique for laparoscopic cholecystectomy but in some cases we used the three-port technique Tense gall bladder was decompressed by pushing a spinal needle \{Figure 1 \} or a 5-mm trocar through the fundus of the gall bladder A combination of sharp and blunt dissection was used to dissect the Calot's triangle Gall bladder was extracted in latex glove A subhepatic drain was placed in all cases.

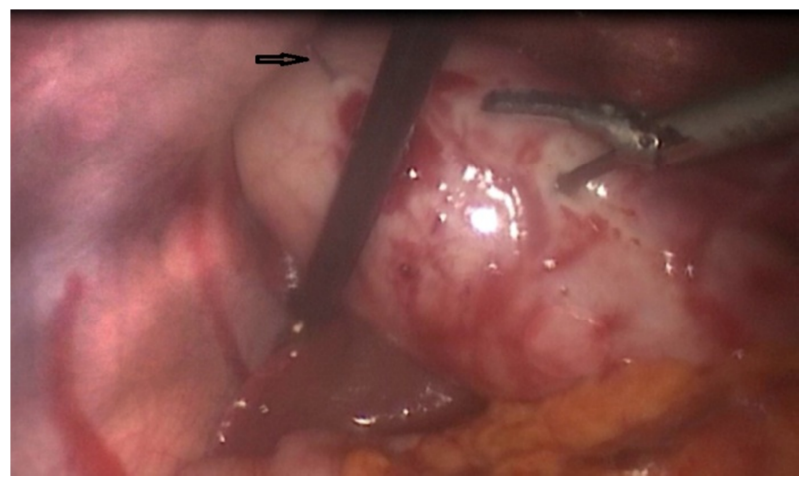

Figure 1. An intraoperative photograph showing a tense gall bladder just before being decompressed by pushing a spinal needle \{the arrow\}.

Postoperatively, the patients were allowed oral intake 6$12 \mathrm{~h}$ after surgery provided they had neither nausea nor vomiting The patients were discharged once the patients were afebrile and taking nutrition orally.

ERCP was performed in patients with bile duct stones (preoperative ERCP in 2 cases in delayed group) and those who developed postoperative bile leak (postoperative ERCP in one patient in early group) Bile leak was defined clinically as a persistent leak of bile through the subhepatic drain for more than 6 weeks Chest infection was diagnosed on the basis of three or more of the findings including cough, phlegm, shortness of breath, chest pain, temperature above $38^{\circ} \mathrm{C}$, and pulse rate above 100 beats per minute Surgical site infection was also recorded.

Statistical analysis was performed using paired -test and chi-square test SPSS version 18 (SPSS Inc., Chicago, IL, USA) was used to determine $\mathrm{p}$ value ( $\mathrm{p}$ value less than 0.05 was considered significant).

\section{Results}

There were 30 males and 90 females with a median age of 51 years (range, 20-82 years) Male to female ratio was 1:3 The demographic details are given in Table 1 Two patients in early group and two patients in delayed group underwent conversion to open surgery ( $P$ value: 0.555 ) due to difficult anatomy and bloody field which causes difficult visualisation \{Figure 2$\}$.

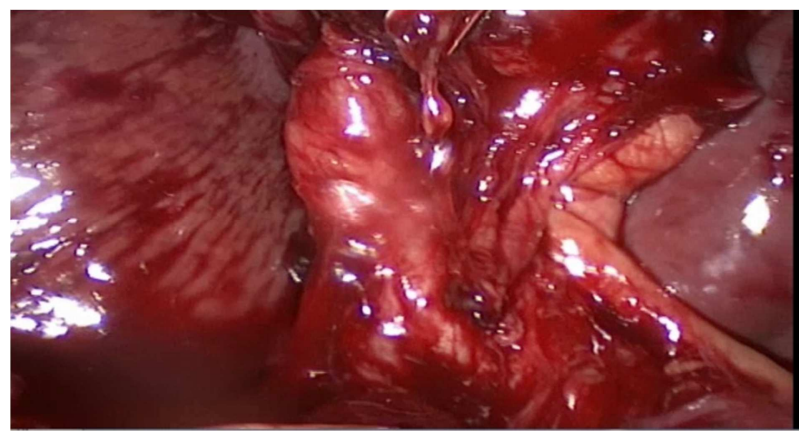

Figure 2. An intraoperative photograph showing difficult anatomy at the field of the Calot's triangle. 
Longer operation time was required in the ELC than in DLC The median operative time was 85 min in ELC and 70 min in DLC The difference in operative time was statistically significant (P value: 0.023 ).

Pre-operative ERCP was required in 2 patients in delayed group These patients had deranged liver function tests with evidence of dilated common bile duct on ultrasound scan Postoperative ERCP was required in 2 patients in early group and 1 patient in delayed group, who had postoperative persistent bile leak and, as a result, investigated with ERCP No major bile duct injury was identified There was leakage from the cystic duct stump, a stent was placed at ERCP and the leak was controlled effectively Operative details are shown in Table 2.

Table 1. Demographic data of studied cases.

\begin{tabular}{|c|c|c|}
\hline \multirow[t]{2}{*}{ Age } & Median & 51 \\
\hline & Range & $20-82$ \\
\hline \multirow[t]{2}{*}{ Sex } & Male & 30 \\
\hline & Female & 90 \\
\hline $\begin{array}{l}\text { Median time between onset } \\
\text { of symptoms and surgery: }\end{array}$ & 4 days (range $1-7$ days) & \\
\hline \multicolumn{3}{|c|}{ Events in waiting period of DLC group: } \\
\hline & Lost follow-up & 10 patients. \\
\hline & Urgent cholecystectomy & 5 patients. \\
\hline & Acute pancreatitis & 3 patients. \\
\hline & Another acute attack. & 5 patients. \\
\hline \multicolumn{3}{|c|}{ Previous admission (48 patients $(40 \%))}$. \\
\hline & No previous admission & 102 patients. \\
\hline & once & 30 patients. \\
\hline & Twice & 10 patients \\
\hline & More than twice & 8 patients. \\
\hline
\end{tabular}

Table 2. Operative findings and complications.

\begin{tabular}{llll}
\hline & $\begin{array}{l}\text { ELC group } \\
(\mathbf{n = 5 0 )}\end{array}$ & $\begin{array}{l}\text { DLC group } \\
(\mathbf{n = 7 0 )}\end{array}$ & P value \\
\hline Operative time & Mean $85 \pm 5.6$ & Mean $70 \pm 4.5$ & 0.023 \\
Conversion rate & 2 & 2 & 0.555 \\
Biliary leakage & 2 & 1 & 0.375 \\
Surgical site infection & 1 & 0 & 0.417 \\
Chest infection & 2 & 3 & 0.656 \\
Port site hernia & 1 & 0 & 0.417 \\
Post operative ERCP & 2 & 1 & 0.375 \\
& Median $=2$ & Median $=1.5$ & \\
Post operative hospital & days & days & 0.375 \\
stay & $\begin{array}{l}\text { Range, 1-10 } \\
\text { days }\end{array}$ & Range, 1-10 days & \\
\hline
\end{tabular}

The median time from onset of symptoms to surgery was 4 days (range, 1-7 days) in early group $40 \%$ of patients (48) had previous admissions with similar symptoms ( 30 had one prior admission, 10 had two and 8 had more than two previous admissions).

In early group, there were one cases of wound infection One patient was re-admitted because of umbilical port site hernia 2 patients developed chest infection postoperatively and all were managed successfully with antibiotics and chest physiotherapy In delayed group, 3 patients developed chest infection postoperatively The median hospital stay was 2 days in early group and 1.5 days in delayed group (Range, 110 days) This difference was statistically insignificant ( $\mathrm{p}$ vale $0.375)$

\section{Discussion}

Arguments made against early laparoscopic cholecystectomy include a high conversion rate and complications Surgical intervention after the first 96 hours of onset of symptoms has been reported as difficult due to significant adhesions [9-10] and is associated with a higher conversion rate [11] The conversion rates for elective laparoscopic cholecystectomy are 4-5\% [12] However, the average reported rates for laparoscopic cholecystectomy in acute cholecystitis are between $10-30 \%$ and can be much higher in patients with empyema or gangrenous gall bladder [6-13].

It is, therefore, argued that if delayed laparoscopic cholecystectomy leads to a technically easier surgery with a lower conversion rate, it may be a better treatment option for acute cholecystitis However, there is an increased risk of gallstone-related morbidity during the waiting period for cholecystectomy.

However, with increasing experience of the surgeons with laparoscopic procedures and advances in the imaging techniques and operating instruments, laparoscopic cholecystectomy is increasing applicable in the setting of acute cholecystitis [14].

González-Rodríguez et al [15], concluded that there is no advantage to delay cholecystectomy for acute cholecystitis on the basis of outcomes in complications, rate of conversion to open surgery, and mean hospital stay Skouras et al [16], conclude that there is strong evidence that early laparoscopic cholecystectomy for acute cholecystitis offers an advantage in the length of hospital stay without increasing the morbidity or mortality The operating time in ELC can be longer, however the incidence of serious complications (i.e common bile duct injury), is comparable to the DLC group Larger randomized studies are required before solid conclusions are reached.

Gutt $\mathrm{CN}$ et al [17] believe that immediate laparoscopic cholecystectomy should become therapy of choice for acute cholecystitis in operable patients, as; laparoscopic cholecystectomy in their study within 24 hours of hospital admission was shown to be superior to the conservative approach concerning morbidity and costs Also, Barcelo et al [18] concluded that, early cholecystectomy in acute cholecystitis can reduce the hospital stay without increase of the conversion rate or complications.

In a systematic review done by Gurusamy et al [19], to compare early laparoscopic cholecystectomy (less than seven days of clinical presentation with acute cholecystitis) versus delayed laparoscopic cholecystectomy (more than six weeks after index admission with acute cholecystitis) A total of 488 participants with acute cholecystitis were randomised to early laparoscopic cholecystectomy ( 244 people) and delayed laparoscopic cholecystectomy (244 people) in the six trials 
They found no significant difference between early and late laparoscopic cholecystectomy Early laparoscopic cholecystectomy during acute cholecystitis seems safe and may shorten the total hospital stay The majority of the important outcomes occurred rarely It is unlikely that future randomised clinical trials will be powered to measure differences in bile duct injury and other serious complications since this might involve performing a trial of more than 50,000 people, but several smaller randomised trials may answer the questions through meta-analyses.

Zhou GH et al [20], performed meta-analysis included seven trials with 1106 patients There was no significant difference between the two groups in terms of bile duct injury or conversion to open cholecystectomy The total hospital stay was shorter by 4 days for early laparoscopic cholecystectomy.

In retrospective cohort study of de Mestral et al [21], from 22,202 patients, a well-balanced matched cohort, 14,220 patients was defined for early cholecystectomy (within 7 days from clinical presentation) was associated with a lower risk of major bile duct injury, or death Total hospital length of stay was shorter with early cholecystectomy No significant differences were observed in conversion rate.

We agree with other studies [6, 22-23] that, prompt laparoscopic surgery for acute cholecystitis reduces readmission rates and enables the patient to return to normal activity and work, whilst limiting the morbidity from their gall bladder disease In the waiting period of delayed group in our study, 10 patients lost follow up, 5 patients need urgent cholecystectomy, 3 patients had attack of acute pancreatitis and 5 patients had another acute attack.

Two patients in early group and two patients in delayed group underwent conversion to open surgery ( $P$ value: 0.555 ) due to difficult anatomy and bloody field which causes difficult visualisation This difference is insignificant We believe that conversion to open procedure is inevitable in laparoscopic management of acute cholecystitis and is not considered a complication.

Bile leak and bile duct injury are the two most feared complications of laparoscopic cholecystectomy for acute cholecystitis; the reported incidence for bile leaks after laparoscopic cholecystectomy for acute cholecystitis is around $0.25 \%$ for elective laparoscopic cholecystectomy but rises to $2-3 \%$ in the presence of acute inflammation [11-24].

We had 2 patients with bile leak in ELC and 1 patient in DLC but without any major bile duct injury: this compares favorably with the published literature.

In delayed group, two patients suspected of having common bile duct stones based on abnormal liver function tests, dilated common bile duct and evidence of ductal calculi underwent pre-operative ERCP.

The technical difficulty of laparoscopic cholecystectomy is related to operative findings during early surgery A distended and edematous gall bladder is commonly seen in cases of acute cholecystitis For good exposure of Calot's triangle, decompression of the gallbladder should be done early because this allows better grasping and retraction of the gallbladder.
In our study, decompression of the gallbladder was required for $40 \%$ of the patients in the early group Stone spillage was seen in $20 \%$ of the cases in the early group A subhepatic drain was fixed in all cases.

We agree with other studies that ELC needs longer operative time than DLC ( 85 vs 70 minutes) Our experience supports the belief that the inflammation associated with acute cholecystitis creates an edematous plane around the gallbladder which facilitates its dissection Waiting for the inflamed gallbladder to "cool down" allows that plain to be fibrotic.

\section{Conclusion}

Early laparoscopic cholecystectomy is feasible and safe for uncomplicated acute cholecystitis Delayed laparoscopic cholecystectomy is not associated with a lower conversion rate than that associated with early laparoscopic cholecystectomy Early laparoscopic surgery offers definitive treatment at the initial admission and avoids the problems of failed conservative management and recurrent symptoms, which require emergency surgery Furthermore, early surgery is associated with a much shorter overall hospital stay, which is a major economic benefit to both the patient and health care system.

\section{References}

[1] Hartwig W, Büchler MW.: Acute cholecystitis: early versus delayed surgery Adv Surg. 2014; 48: 155-64.

[2] Cuschieri A Approach to the treatment of acute cholecystitis: open surgical, laparoscopic or endoscopic? Endoscopy 1993; 25: $397-8$.

[3] A. Cuschieri, F Dubois, J Mouiel et al., "The European experience with laparoscopic cholecystectomy," American Journal of Surgery, vol 161, no 3, pp 385-387, 1991.

[4] Berci G, Sackier JM The Los Angeles experience with laparoscopic cholecystectomy Am J Surg 1991; 161: 382-4.

[5] Kum C, Goh P, Issac J, Tekant Y, Ngoi S Laparoscopic cholecystectomy for acute cholecystitis Br J Surg 1994; 81: $1651-4$.

[6] Lai PB, Kwong KH, Leung KL, Kwok SP, Chan AC, Chung $\mathrm{SC}$ et al Randomised trial of early versus delayed laparoscopic cholecystectomy for acute cholecystitis.Br J Surg 1998; 85: 764-7.

[7] Koo K, Thirlby R Laparoscopic cholecystectomy in acute cholecystitis What is the optimal timing for operation? Arch Surg 1996; 131: 540-4.

[8] Knight J, Mercer S, Somers S, Walters AM, Sadek SA, Toh SK Timing of urgent laparoscopic cholecystectomy does not influence conversion rate Br J Surg 2004; 91: 601-4.

[9] Bickel A, Rappaport A, Kanievski V, Vaksman I, Haj M, Geron $N$ et al Laparoscopic management of acute cholecystitis Prognostic factors for success Surg Endosc 1996; 10: $1045-9$. 
[10] Teixeira JP, Saraiva AC, Cabral AC, Barros H, Reis JR, Teixeira A Conversion factors in laparoscopic cholecystectomy for acute cholecystitis Hepatogastroenterology 2000; 47: 626-30.

[11] Garber S, Korman J, Cosgrove J, Cohen J Early laparoscopic cholecystectomy for acute cholecystitis Surg Endosc 1997; 11: 347-50.

[12] Larson GM, Vitale GC, Casey J, Evans JS, Gilliam G, Heuser $\mathrm{L}$ et al Multi-practice analysis of laparoscopic cholecystectomy in 1983 patients Am J Surg 1992; 163: 2216.

[13] Chandler CF, Lane JS, Ferguson P, Thompson JE, Ashley SW Prospective evaluation of early versus delayed laparoscopic cholecystectomy for treatment of acute cholecystitis Am Surg 2000; 66: 896-900.

[14] Kiviluoto T, Siren J, Luukkonen P, Kivilaakso E Randomised trial of laparoscopic versus open cholecystectomy for acute and gangrenous cholecystitis Lancet 1998; 351: 321-5.

[15] González-Rodríguez $\mathrm{FJ}^{1}$, Paredes-Cotoré JP, Pontón C, Rojo Y, Flores E, Luis-Calo ES, Barreiro-Morandeira F, Punal JA, Fernández A, Paulos A, Santos F,Cainzos M.: Early or delayed laparoscopic cholecystectomy in acute cholecystitis? Conclusions of a controlled trial Hepatogastroenterology. 2009 Jan-Feb; 56(89): 11-6.

[16] Skouras C1, Jarral O, Deshpande R, Zografos G, Habib N, Zacharakis E Is early laparoscopic cholecystectomy for acute cholecystitis preferable to delayed surgery? Best evidence topic (BET) Int J Surg. 2012; 10(5):250-8 doi: 10.1016/j.ijsu.2012.04.012 Epub 2012 Apr 21.

[17] Gutt CN, Encke J, Köninger J, Harnoss JC, Weigand K,
Kipfmüller K, Schunter O, Götze T, Golling MT, Menges M, Klar E, Feilhauer K, Zoller WG, Ridwelski K,Ackmann S, Baron A, Schön MR, Seitz HK, Daniel D, Stremmel W, Büchler MW.: Acute cholecystitis: early versus delayed cholecystectomy, a multicenter randomized trial (ACDC study, NCT00447304) Ann Surg. 2013 Sep;258(3):385-93 doi: 10.1097/SLA.0b013e3182a1599b.

[18] Gurusamy KS, Davidson C, Gluud C, Davidson BR.: Early versus delayed laparoscopic cholecystectomy for people with acute cholecystitis Cochrane Database Syst Rev. 2013 Jun 30; 6:CD005440 doi: 10.1002/14651858.CD005440.pub3.

[19] Zhou, M W., X D Gu, et al "Comparison of clinical safety and outcomes of early versus delayed laparoscopic cholecystectomy for acute cholecystitis: a meta-analysis." Scientific World Journal 2014: 274516.

[20] de Mestral C1, Rotstein OD, Laupacis A, Hoch JS, Zagorski B, Alali AS, Nathens AB Comparative operative outcomes of early and delayed cholecystectomy for acute cholecystitis: a population-based propensity score analysis Ann Surg. 2014 Jan; 259(1):10-5 doi: 10.1097/SLA.0b013e3182a5cf36.

[21] Sobolev B, Mercer D, Brown P, Fitzgerald M, Jalink D, Shaw $\mathrm{R}$ Risk of emergencyadmission while awaiting elective cholecystectomy Can Med Assoc J 2003; 169: 662-5.

[22] Serralta A, Bueno J, Planells M, Rodero D Prospective evaluation of emergency versus delayed laparoscopic cholecystectomy for early cholecystitis Surg Laparosc Endosc Percutan Tech 2003; 13: 71-5.

[23] Unger W, Glick G, Landeros M Cystic duct leak after laparoscopic cholecystectomy: a multi-institutional study Surg Endosc 1996; 10: 1189-93. 